For: Dutt, Amitava and Benjamin Radcliff (eds.). Happiness, Economics and Politics. Cheltenham, U.K. and Northampton, MA: Edward Elgar.

\title{
HAPPINESS When TEMPTATION OVERWHELMS WILLPOWER
}

\author{
Alois Stutzer* \\ University of Basel \\ May 13, 2008
}

\begin{abstract}
The economics of happiness is applied to further the understanding of important consumption decisions in which limited willpower is often argued to lead to suboptimal choices. Based on individuals' judgments of the quality of their lives, it is, in principle, possible to derive whether some observed behavior is suboptimal and is therefore reducing a person's welfare. We discuss the key characteristics and the normative basis of the approach including the evaluation metric and issues of empirical identification. In addition, evidence on willpower and subjective well-being for three important domains of consumption is presented, i.e., TV viewing, smoking and eating.
\end{abstract}

JEL classifications: D01, D11, D12, D60, D91, I18

Keywords: revealed preference, willpower, self-control problem, individual welfare, subjective well-being, smoking, TV viewing, obesity

\footnotetext{
* Address: Department of Business and Economics, University of Basel, Petersgraben 51, CH4003 Basel, Switzerland. Phone: 0041-(0)61 26733 61, fax: 0041-(0)61 26733 40, email: alois.stutzer@unibas.ch. I am grateful to Thomas Brändle, Bruno Frey and Michael Zehnder and the participants of the Conference on New Directions in the Study of Happiness at the University of Notre Dame for helpful comments.
} 


\section{Introduction}

Saint Anthony of Egypt was tempted by the devil, who appeared in the guise of a monk offering Anthony bread while he was fasting. Anthony overcame the temptation and pursued his long-term plans. As mere mortals we sometimes lack the willpower to withstand the seductions of window displays, to curb our hunger for salty and fatty titbits, to control antisocial emotions, etc. Accordingly, some of us end up obese, addicted to drugs, indebted, with poor job market outcomes, or with unsuccessful relationships. Independently of whether the involved behavior is perceived morally condemnable, it is often understood to reduce individuals' welfare. But how do we know that some choices are suboptimal according to people's own evaluation? On what foundation do we judge whether people make mistakes?

Addressing these questions is highly relevant for public policy if the goal is to understand environments that make people best off. If some choices are suboptimal, conditions can be searched for that make these mistakes less likely.

The scientific analysis of suboptimal choices is not an easy task though. The rational choice perspective in traditional economic theory is purely equipped to offer guidance in studying systematic errors in consumption choice. According to its basic view, individuals know what they choose. They are able to predict costs and benefits of pursuing some activity or consuming some good now and in the future. After people have chosen some options, these options are implemented without problems. The preferred course of action can be pursued and people's behavior in expectations maximizes their welfare. This implies that behavior reveals consistent preferences. Systematic errors in consumption choice are thus ruled out by assumption. This approach makes it almost impossible to detect and understand suboptimal consumption decisions due to problems of, e.g., limited willpower. ${ }^{1}$

We propose the economics of happiness ${ }^{2}$ as an alternative approach to study phenomena where temptation might overwhelm willpower. This chapter contributes to the crossdisciplinary field of economics and psychology (see, e.g., Rabin 1998, Camerer et al. 2004, De Cremer et al. 2006 and Frey and Stutzer 2007) and establishes a closer link between the

\footnotetext{
${ }^{1}$ In a recent debate on behavioral welfare economics, the possibilities and limits of a choice based approach to identify mistakes have been controversially discussed (see Bernheim and Rangel 2007, Gul and Pesendorfer 2007 and Koszegi and Rabin 2007).

${ }^{2}$ For an introduction to the economics of happiness, see, e.g., Frey and Stutzer (2002a,b), Layard (2005) and Frey (2008).
} 
study of suboptimal choices and the research on subjective well-being (see also Hsee et al. 2008). Based on individuals' judgments of the quality of their lives, it is, in principle, possible to derive whether some observed behavior is suboptimal and is therefore reducing a person's welfare. This approach draws on empirical research in which the dependent variable is reported subjective well-being or life satisfaction and consumption behavior serves as main explanatory variable. This approach is promising as it puts forward a proxy for individuals' welfare to evaluate choice behavior. However, the approach is subject to the same econometric difficulties faced by studies that examine the determinants of behavior, i.e. the possibility of omitted variable bias and endogeneity bias.

Here, the economics of happiness is applied to further the understanding of important consumption decisions. We mention recent evidence on TV viewing and smoking. In more detail, we discuss eating habits in Western countries where obesity has become a major health issue. Research in economics has provided important insights how technological progress reduced the relative price of food and contributed to the increase in obesity. However, the increased availability of food might well have overstrained willpower and led to suboptimal consumption decisions relative to people's own standards. It is indeed found that obesity decreases the well-being of individuals who report limited self-control while it does not so for others.

In the following section II, theoretical and empirical challenges of using the happiness approach to study suboptimal choices are discussed. First, the key characteristics and the normative basis of the approach based on individuals' judgments about the quality of their lives are disclosed. Second, issues in the empirical identification are raised. Section III to V present evidence on willpower and subjective well-being for three important domains of consumption: TV viewing, smoking and eating. Section VI offers concluding remarks.

\section{The Happiness Approach to Suboptimal Decisions and Individual Welfare}

\subsection{Normative basis and evaluation metric}

\section{Limits of the revealed preference approach}

The normative basis of the study of consumer choice in economics is the idea of consumer sovereignty. Individuals' choices are considered to be the result of rational utility 
maximization. This view is, however, challenged by research in economics and psychology that reports a large number of different anomalies in a real-life decision-making context. Anomalies are understood in the sense of individual behavior violating certain axioms underlying the rational consumer hypothesis (Kahneman et al. 1991). One of the most challenging deviations from utility maximizing consumption choice is due to people having limited willpower.

Standard economics is mute about willpower and assumes that people are able to make and implement decisions according to their long-term preferences. Viewed this way, consuming goods and pursuing activities that some people consider addictive, or at least forming bad habits, such as smoking cigarettes or taking cocaine, watching TV or driving expensive cars are considered a rational act. Contrary to this view, many people judge their own and other people's consumption behavior as irrational in the sense that they think that they would be better off if they would consume less of these goods and care more for their future well-being. Such self-control problems involve two aspects: myopia and procrastination. In both cases, the present is emphasized at the expense of the long-term. When affected by myopia, people focus on consuming in the present and lack discernment or long-range perspective in their thinking and planning, thus undermining their well-being over time. In this respect, generally goods offering immediate benefits at negligible immediate marginal costs are tempting. Procrastination focuses on putting off or delaying an onerous activity more than a person would have liked when having evaluated it beforehand. In other words, willpower is necessary to stand temptations to fulfill immediate desires that conflict with long-term goals. ${ }^{3}$ Based on revealed preference, it is difficult, if not impossible, to discriminate between the view of consumers as rational sovereign actors and consumers facing limited willpower.

\section{Promises of a complementary happiness approach}

Two extensions of the traditional emphasis on ex ante evaluation and observed decision are insightful in the study of individual welfare. First, the standard economic concept of revealed preference is complemented with the concept of individual judgment on the quality of one's life, what might be called the happiness approach. This separation of concepts makes it

\footnotetext{
3 In economics, time inconsistent preferences are most prominently formulated in models of hyperbolic discounting (see, e.g., Laibson 1997). A low discount factor (i.e. a discount factor decreased by $\beta, \beta \in(0,1))$ is applied between the present and some point in time in the near future and a constant discount factor $\delta$ thereafter. An excellent account of the recent extensive empirical and theoretical literature on time inconsistent preferences is provided in Frederick et al. (2002).
} 
possible that judgments about experiences systematically diverge from orderings of options derived from observed behavior. The second extension is closely related to the first, and emphasizes ex post evaluations as a valuable source of information about the possibility of bounded rationality in people's decision-making. How do people fare and judge their situation after they have made decisions?

The key idea is thus that judgments on people's life are captured as a proxy for their individual welfare. Thereby the standards underlying people's judgment are assumed to be those that the individual would like to pursue in order to maximize welfare. Thus the identification of mistakes hinges on the presumption that individuals pursue individual welfare based on some stable evaluation standards. Moreover, whether mistakes are properly identified depends on whether the evaluation metric fits people's judgment of their life.

The normative basis of the approach thus goes beyond assuming the pursuit of happiness but also involves the choice of the concrete evaluation metric to elicit people's judgments. ${ }^{4}$ Thus ambiguities remain when choosing the empirical concept in order to measure individual welfare. ${ }^{5}$ Some people might favor a distant look reflecting on one's life after the fact, while others favor the reasoned ex ante evaluations as their standards. Still others might give priority to how they felt when experiencing the course of life.

Imagine those people who see happiness or high individual welfare as something like the "positive, persistent attitude towards both particular experiences and life experience more generally that a person feels upon repeated reflection" (Kelman 2005, p. 408f). For them, general evaluations of their satisfaction with life as a whole might be an appropriate metric to capture judgments about individual welfare.

For those people who equate individual welfare with moment-to-moment affect, individual welfare might be measured relatively best by approaches like the experience sampling method (Csikszentmihalyi and Hunter 2003, Scollon et al. 2003) or the day reconstruction method (Kahneman et al. 2004). The relevance of the (normative) choice of an elicitation mechanism is underscored for the specific application to willpower. While the benefits of immediate gratification seem easily accessible in moment-to-moment measurement of individual affect,

\footnotetext{
${ }^{4}$ An excellent account of the ambiguities of welfare in the context of economics and hedonic psychology is provided in Kelman (2005).

${ }^{5}$ There is in fact a debate in happiness research about how to measure subjective well-being that might be better understood from the angel of proponents' preferred welfare concept (see Helliwell 2006, Kahneman and Riis 2005 and Kahneman et al. 2004).
} 
this same measure is likely to miss the value that people attribute to resisting a temptation and to exercising willpower. When looking for an empirical tool to collect information about people's judgment, it is thus important to reveal the concrete metric.

\subsection{Empirical identification of suboptimal choices due to limited willpower}

Before we discuss the testing strategies based on individual welfare judgments, we briefly mention two previous approaches. Both of them look for patterns of behavior that cannot easily be reconciled with standard utility maximization.

\section{Prediction of behavior with indicators of limited self-control}

This approach starts out with a standard model of individual behavior. It is studied whether the explanatory power of the (empirical) model is increased when the variation in people's level of self-control is taken into account. Empirically, limited self-control is captured (i) by using behavioral markers, like not having a bank account or having had many hangovers from alcohol consumption in the recent past (see, e.g., DellaVigna and Paserman 2005), (ii) by letting people in experiments choose between immediate payoffs and higher delayed payoffs (Thaler 1981), or (iii) by measures of self-report. There is a rich literature in psychology on developing and applying survey measures of self-control (e.g. Tangney et al. 2004) or related psychological measures like conscientiousness ${ }^{6}$ (for an application in economics, see Ameriks et al. 2007) and mastery ${ }^{7}$. In addition, there are more specific survey measures relying on scenarios (Ameriks et al. 2007) or direct reporting of self-control problems in some specific aspect of consumption.

\section{Self-infliction of costs}

A problem of self-control is diagnosed if people are observed spending a lot of time or money on changing their behavior. For instance in the context of obesity, this 'smoking gun' approach looks for evidence like, e.g., spending a lot of money on staying at a clinic where mainly sugarless tea is served. More generally, self-binding mechanisms are voluntarily

\footnotetext{
6 "Conscientiousness describes socially prescribed impulse control that facilitates task- and goaldirected behaviors, such as thinking before acting, delaying gratification, following norms and rules, and planning, organizing, and prioritizing tasks" (John and Srivastava 1999, p. 121).

7 "Mastery refers to the extent to which people see themselves as being in control of the forces that importantly affect their lives" (Pearlin et al. 1981, p. 340).
} 
chosen to reduce the utility of some activity or to make short-term revisions of consumption plans less attractive.

\section{Ex post evaluation based on individual judgments on the quality of one's life}

This approach puts forward a proxy for individual welfare to evaluate choice behavior. Expressed in simple terms, it is studied whether some specific behavioral patterns are related to higher or lower reported subjective well-being. However, the approach is subject to the same econometric difficulties faced by studies that examine the determinants of behavior, i.e. the possibility of omitted variable bias and endogeneity bias. Two specific strategies to deal with the issue of endogeneity will be discussed in the following sections on TV viewing and smoking.

In this section, a general strategy is proposed that combines various sources of information to what might be called a thick description of limited willpower and subjective well-being. It is studied whether the ex post evaluation of some behavior systematically varies between groups of people who have differing amounts of willpower. As we will apply this approach to the phenomenon of obesity in section $\mathrm{V}$, it is also introduced in this context in order to clarify the ideas and arguments. The central hypothesis states obesity makes people worse off in terms of reported subjective well-being if the increased body mass is due to a self-control problem. However, if people are not lacking willpower, a BMI above 30 does not enter negatively into the evaluation of people's well-being. Any correlation between the level of willpower and subjective well-being as such is statistically captured in the constant term.

Three comments serve to clarify the underlying assumptions, strengths and weaknesses of the approach:

1. It is no problem for the approach if - in terms of an application to obesity - fat people are jollier. The approach does not rely on a specific benchmark correlation between the phenomenon under study and subjective well-being. A strong preference for food (and thus a higher BMI) can be positively or negatively correlated with reported well-being. It is predicted that obese people judge their overall well-being less favorably than people of normal weight when they indicate limited willpower rather than when they do not.

2. The approach explicitly and directly tests for effects on individual welfare. Importantly, individuals are free to judge and evaluate a certain life-path. This involves, e.g., the weighting of short-term pleasures versus the pursuit of long-term goals. 
3. The testing strategy relies on two qualities of the self-control problem under study. First, individuals are aware of their limited willpower (as self-reports are used). Second, selfcontrol behavior is generalized across different consumption decisions. This means that limited willpower affects behavior across-the-board.

Depending on the application, this latter assumption might be questionable. In the case of obesity, it means that a high BMI need not be positively correlated with the exertion of willpower in other areas. There is, however, the possible scenario that people prefer to be weak-willed and fat rather than to be weak-willed and a chain smoker. Weak-willed people who are obese would then not necessarily judge their well-being less favorably than those who are not obese, and the testing strategy fails to identify limited willpower reducing individual welfare.

The assumption that self-control behavior generalizes across activities, however, can be relaxed in the concrete application. Consumption activities that are close substitutes for people with limited willpower can be simultaneously taken into account in the empirical analysis.

In sum, this general strategy combines the idea of exploiting supplementary information on the variation in a person's level of willpower and the idea of an ex post evaluation based on reported subjective well-being.

\section{TV Viewing}

\subsection{A controversial mass phenomenon}

There are countries where people over their life time spend as many hours watching TV as they devote to paid work (Corneo 2005). TV viewing is thus by far the most important leisure time activity in modern societies. The largest number of heavy TV viewers ${ }^{8}$ in Europe is found in Greece. As much as 36.8 percent of the population (age 15 and older) reports that they spend 3 hours a day or more watching TV. At the other end of the ranking, there are 8.4 percent heavy TV viewers in Switzerland (Frey et al. 2007 based on the European Social Survey). Revealed preference therefore suggests that, for many people, TV consumption is an important source of well-being. This assessment is in contrast to the mixed appraisal of TV 
viewing in society. Television has been called a 'plug-in-drug', keeping people glued to the screen and impeding the enjoyment of more valuable experiences. Accordingly, the expansion of TV consumption has a negative connotation, being associated with a decline in social capital, an increase in violence and crime, and a weakening of democracy. ${ }^{9}$ In sum, there is a strong popular notion that people watch too much TV. They watch more than they would like to watch, both ex ante and ex post..$^{10}$

The reason why TV may lend itself to over-consumption is mainly due to the immediate benefits and the negligible immediate marginal cost of engaging in this activity. One just has to push a button. In contrast to going to the cinema, the theater or any outdoor activity, there is no need to be appropriately dressed before leaving the house, and there is no need to buy a ticket or to reserve a seat in advance. Watching TV does not require any special physical or cognitive abilities (Kubey and Csikszentmihalyi 1990: 173). Unlike other leisure activities, TV viewing does not need to be coordinated with other persons. It is quite possible to sit alone in front of the TV, while other leisure activities, such as tennis or golf, require a partner with similar time availability and similar preferences. As a consequence, watching TV has, compared to other leisure activities, an exceedingly low or nonexistent entry barrier. At the same time, it offers entertainment value and is considered to be one of the best ways of reducing stress. Moreover, while watching TV, immediate marginal costs are even lower and having a remote control is an invitation to ultra short-term optimization (zapping). Many of the costs resulting from such consumption behavior are not experienced immediately, or not predicted at all. These characteristics of the consumption good induce many individuals to fall prey to excessive TV viewing.

Here, the role of limited willpower in TV viewing is addressed with regard to consumers' welfare. It is hypothesized that, for people facing similar restrictions, heavy TV viewing indicates overstrained willpower rather than a love of TV. Accordingly, heavy TV consumption is expected to result in lower reported subjective well-being. In such a situation,

\footnotetext{
${ }^{8}$ By "heavy TV viewers", people are meant who spend a great deal of time watching TV, and not TV viewers who are overweight (although watching a lot of TV is sedentary and invites people to snack, which can in turn lead to obesity).

${ }^{9}$ The case for negative impacts of TV consumption on society is, e.g., made by Kubey (1996), Putnam (2000), Sparks and Sparks (2002) and Gentzkow (2006).

${ }^{10}$ Regarding television consumption, there is some (anecdotal) evidence that individuals may have self-control problems. $40 \%$ of US adults and $70 \%$ of US teenagers admit that they watch too much TV (Kubey and Czikszentmihalyi 2002).
} 
an increase in the price of TV viewing would be expected to increase the well-being of TV viewers with a self-control problem as the higher price were to serve as a self-binding mechanism (analogous to the argument in Gruber and Mullainathan 2005). For most consumers, the price of viewing an additional hour of TV, however, is zero. It is thus not easy to pursue this empirical approach to test the rational consumer hypothesis (at least as long as pay per view is not more common). An interesting alternative might be the extreme case of no TV. While it is definitely not optimal, it might be attractive compared to unrestrained consumption. The introduction of TV would represent a situation for a possible comparison. However, in most countries, this technological innovation gained ground too early in the last century in order to be able to match it with data on reported subjective well-being.

There are, however, some natural experiments about access to TV that provide some insights as to the consequences of TV for factors that are closely related to individual well-being. A certain Canadian city was unable to receive any TV signals up until 1973, due to its location in a steep valley. Otherwise, it was similar to two cities in the vicinity used as control cases. A study by Williams (1986) suggests that the introduction of TV crowded out other activities, in particular those outside the home, such as taking part in sports' activities or attending clubs. It also reduced the reading abilities and creative thinking of children and fostered more aggressive behavior and stereotyped ideas about gender roles. TV also reduced the problem solving capacities of adults. Another study by Hennigan et al. (1982), based on a natural experiment, takes a look at the advent of TV in the United States which, due to technical reasons, took place at different times in different places. Petty crime, but not violent crime, increased. Observing the same time period in the US, Gentzkow (2006) finds that the advent of TV reduced voter turnout.

\subsection{The subjective well-being of heavy TV viewers}

Direct evidence on the relationship between TV viewing and reported subjective well-being is scarce. So far, mainly the subjective well-being of heavy TV viewers is analyzed, controlling for many individual characteristics. Such an approach is followed in a large study on TV viewing and life satisfaction for 22 European countries in 2002/03 (Frey et al. 2005). It is found that the more people spend time watching TV, the lower is their reported satisfaction with life, ceteris paribus. The result of the econometric analysis is consistent with the hypothesis that heavy TV viewers suffer significant reductions in their utility because they are 
unable to fully control their TV consumption: They watch too much according to their own evaluation. $^{11}$

Where do the costs of the misallocation of time come from? There are lost alternatives in the present, like engaging in more stimulating activities or socializing. It is, for example, found that people watching a lot of TV spend less time with family and friends and invest less in relational goods in general (Bruni and Stanca 2007). But there are also costs in the future. One might be tired the next morning because of not getting enough sleep. Seen long-term, people might change their beliefs about the world and about the sources of well-being. In particular, the exposure to the healthy, wealthy and good-looking people on TV is expected to increase people's aspirations with regard to their own body, but also with regard to their consumption standard. There is substantial research on the relationship between TV viewing and materialism (e.g. Kasser 2002) and financial satisfaction (Bruni and Stanca 2006; Layard 2005). Most studies find a positive correlation between extensive TV consumption and those outcomes that are related to lower subjective well-being. In the study for 22 European countries mentioned above (Frey et al. 2005), half of the correlation between TV consumption and life satisfaction can be attributed to heavy TV viewers having lower financial satisfaction, attributing more importance to being rich, feeling less safe, trusting other people less and thinking that they are involved less in social activities than their peers. ${ }^{12}$ Because these costs are not experienced immediately, individuals with time inconsistent preferences are unable to adhere to the amount of TV viewing they planned or which, in retrospect, they would consider optimal for themselves.

\subsection{Willpower and the role of the choice set}

An alternative way of testing whether heavy TV viewers experience reduced individual wellbeing because of their consumption choice refers to people's opportunity set. Benesch et al. (2006) study whether the effect of having a larger number of TV channels available, i.e. a larger choice set, raises people's subjective well-being, as would be expected by standard economic theory. The expansion and diversification of media supply, due to VCR, cable or satellite has, in many countries, gone hand in hand with increased television viewing time

\footnotetext{
${ }^{11}$ However, the potential correlation is also consistent with a hypothesis according to which unhappy people resort to TV viewing. This might lead to a mutually reinforcing relationship.

${ }^{12}$ While these correlations are suggestive, it has to be kept in mind that third factors could be driving differences in the different attitudes as well as in TV viewing.
} 
(see the collected studies in Becker and Schoenbach 1989). Again, the longer time spent in front of the TV set is consistent with rational consumers, as well as with TV viewers who are subject to a self-control problem. A study on the introduction of cable TV in Israel (comparing neighborhoods with a difference-in-difference approach) reports people's evaluation of their consumption choice (Weimann 1996). It is found that, with cable TV and thus more channels, there is a significant increase in the percentage of viewers agreeing to the statements "I often watch television more than I intend to" (28\% before cable introduction and $41 \%$ one year after) and "watching television is often a waste of time" ( $24 \%$ before cable introduction and $36 \%$ after). The expanded choice set due to the technological change seems to have led to an increase in the number of people watching more TV than they planned to, or more than they think is good for them. ${ }^{13}$

Benesch et al. (2006) test the hypothesis based on recent data from the European Social Survey, World Values Survey and Television Key Facts from IP Germany. In a first step, consumers who possibly have a self-control problem are identified as those people with a large positive residual in a regression explaining the amount of TV viewing according to individual socio-demographic characteristics (referred to as "heavy viewers"). In a second step, the effect of a higher number of TV channels on subjective well-being is estimated for heavy TV viewers in comparison with moderate TV viewers. Based on more than 70,000 individual observations from 45 country samples, they find a statistically significantly negative interaction term between (residual) TV viewing and the number of TV channels, and calculate a negative marginal effect of additional TV channels on the well-being of heavy viewers. This is consistent with the hypothesis of limited self-control being involved in the phenomenon of mass TV consumption.

\section{Smoking}

Recently, many Western countries have introduced extended smoking restrictions. Based on the standard economic model, we would predict that smokers would heavily oppose them. Smokers could always voluntarily refrain from smoking and these restrictions are thus only perceived as an additional restriction on the choice set. However, if it is taken into account

\footnotetext{
${ }^{13}$ Asking people directly whether they think that they watch too much TV could lead to answers that are motivated by social desirability. It should be noted that surveys on general life satisfaction are less likely to be affected by such a bias, at least not one that is systematically correlated with some specific consumption behavior.
} 
that some smokers might suffer limited willpower to quit smoking, they might welcome smoking restrictions as a kind of self-control mechanism. Hersch (2005), in fact, finds for the United States using data from the Current Population Survey that smokers who plan to quit smoking are more supportive of smoking regulations than are other smokers.

A similar reasoning holds for tobacco taxes. Different behavioral models can make systematically different predictions for the effect of excise taxes on individual welfare, while they may all predict reduced consumption of the good that is taxed. People suffer a loss when a normal good is taxed, but experience increased utility when the tax helps to overcome a bad habit like smoking. Accordingly, people might oppose sin taxes as being discriminatory against particular pleasures in life or advocate them to encourage individuals to improve their lot. In a nutshell, the standard economic model predicts that recent increases in cigarette taxes and restrictions on smoking reduce smoking and make individuals worse off. A model that incorporates limited willpower, however, predicts that smoking is reduced while individual utility might be increased.

Research on happiness can contribute to this debate and directly study the effect of tobacco taxes on people's subjective well-being. In two longitudinal analyses across the US and Canadian states, Gruber and Mullainathan (2005) perform such a test with data from the General Social Survey. They analyze the effect of changes in state tobacco taxes on the reported happiness of people who are predicted to smoke at the prevailing tobacco tax. They arrive at the result that a real cigarette tax of 50 cents $^{14}$ significantly reduces the likelihood of being unhappy among those with a propensity to be smokers. In fact, they would, with a 50 cents tax, be just as likely to report being unhappy as those not predicted to be smokers (i.e. the proportion of smokers in the lowest happiness category would fall by 7.5 percentage points). This result favors models of time-inconsistent smoking behavior, in which people have problems with self-control. ${ }^{15}$ Moreover, the result shows that price increases can serve as a self-commitment device.

\footnotetext{
${ }^{14}$ The average real (in 1999 US\$) cigarette tax in the United States is 31.6 cents in the sample (Gruber and Mullainathan 2005, 5).

${ }^{15}$ In another study, the negative internality from suffering a self-control problem and being a smoker is assessed (Jürges 2004). The monthly compensation required to make a smoker as well off as a nonsmoker is estimated to be approximately Euros 500. However, the effects of smoking on life satisfaction were not identified, based on changes in exogenous conditions restricting the possibilities to smoke.
} 
Problems of self-control with smoking also arise due to temptation (Bernheim and Rangel 2004). Alternative tests would relate the happiness of potential smokers to clean air laws. These tests would capture exogenous changes in cues or moments of temptation. A comparison of results would allow assessing the boundaries of prices as a means of affecting self-regulation.

Research findings on subjective well-being with regard to self-control problems with smoking complement other evidence suggesting self-control problems in a systematic way. There is a large market offering all kinds of drugs and therapies to people who want to stop smoking. In fact, eight out of ten smokers would like to quit smoking and try it every eight and a half months on average (Gruber and Koszegi 2001).

\section{Obesity}

\subsection{Can obesity be explained by genes and relative prices?}

Obesity is on the rise in many Western countries and, with it, illnesses such as diabetes and heart disease. Observers call it an "obesity pandemic", comparable to big threats such as global warming and bird flu, or talk of it as the epidemiological landslide of the last two decades. Overweight and obesity is defined relative to people's weight to height ratio in metric units, as captured in the body mass index $(B M I): B M I=k g / m 2$. Adults with a $B M I \geq 30$ $\mathrm{kg} / \mathrm{m} 2$ are classified as obese and those with a $\mathrm{BMI} \geq 25 \mathrm{~kg} / \mathrm{m} 2$ as overweight. In many European countries, the prevalence of obesity has risen three-fold or more since the 1980s (Sanz-de-Galdeano 2005; WHO Europe 2005). In Europe, adults today have an average BMI of almost 26.5. Worldwide, the percentage of obese adults varies greatly: around 3 percent in South Korea and Japan, 8 percent in Switzerland, over 22 percent in the United Kingdom, and more than 30 percent in the United States (see figure 1). In the United States, adult obesity rates have more than doubled since the 1980s. In the year 2000, three in ten adults were classified as obese (Flegal et al. 2002).

[Figure 1 about here]

Overweight accounts for 10-13 percent of deaths and 8-15 percent of healthy days lost due to disability and premature mortality (DALY) in the European Region (World Health Organization 2002). 
A debate has started about the economic causes of this phenomenon, as well as its consequences (see, e.g., Cutler et al. 2003; Finkelstein et al. 2005; Rashad 2006). Increased obesity has been explained as the relationship between energy expenditure and energy intake. Energy expenditure is lower nowadays because manual labor has been replaced by more sedentary work due to technological changes (Lakdawalla and Philipson 2002). However, this trend started long before the obesity endemic took off. The increase in calories consumed fit the obesity pattern better and is of sufficient magnitude to account for its increased prevalence (Putnum and Allshouse 1999). In particular, higher snack calories are responsible for higher energy intake for men, and for even higher energy intake for women (Cutler et al. 2003).

What is the economic rationale behind the shifting energy household? Looking at relative prices suggests that, since the early 1980s, there has been a decrease in price for calorie-dense foods and drinks compared to fruit and vegetables, which are less energy-dense (Finkelstein et al. 2005). These price reductions were made possible by new technologies in food production, in particular for prepackaged and/or prepared food. People have reacted by eating more frequently (snacking), eating bigger portions and spending less time on preparing meals.

The question arises how these increases in body weight, causing considerable harm to people's health, are to be evaluated. Do people eat too much? What is the standard for "too much" if people can choose when and how much they want to eat? Traditional economics advises us to resort to consumer sovereignty under such conditions. "Even with full information about the benefits of physical activity, the nutrient content of food, and the health consequences of obesity, some fraction of the population will optimally choose to engage in a lifestyle that leads to weight gain because the costs (in terms of time, money, and opportunity costs) of not doing so are just too high" (Finkelstein et al. 2005, p. 252). This might apply even more because health insurances and taxpayers finance a large amount of the monetary costs of obesity. Moreover, obesity can be rationalized, assuming a high discount rate for future outcomes. The argument for variation in individual discount rates as an explanation for increased obesity is put forward, e.g., by Komlos et al. (2004). ${ }^{16}$

However, the possibility of individuals consuming "too much" food is excluded by assumption in the revealed preference approach. Yet, in order to justify this view, one would have to reconcile the prevalence of obesity with other behavioral regularities, like people

\footnotetext{
${ }^{16}$ In an empirical analysis for the Netherlands, Borghans and Golsteyn (2006) conclude, however, that it is unlikely that BMI increased because of an increase in the time discount rate.
} 
spending large sums of money on diets and health clubs, or people's weight yo-yoing as they go from one diet to the next. ${ }^{17}$

An alternative approach accepts that people might face self-control problems when exposed to the temptation of immediate gratification from food when they are hungry or have a craving for something sweet, fatty or salty (see, e.g., Offer 2001). There is a rich literature on the control of eating, emphasizing physiological mechanisms (Blundell and Gillett 2001; Smith 2006). In particular, humans are endowed with a system of weight regulation that favors weight gain over weight loss to reduce any future risk of starvation. While this ability was evolutionary advantageous, it is a challenge to conscious control of food intake today. People consume more food and calories and eat more frequently than what they consider good for themselves when they think about and plan their diet. People are aware of this phenomenon, but more so in others than themselves (Taylor et al. 2006). They judge their own and other people's consumption behavior as irrational in the sense that they think that they would be better off if they would consume less and care more about their future well-being. ${ }^{18}$

\subsection{Previous evidence on obesity and subjective well-being}

Reported subjective well-being provides information about people's evaluation of their situation after they have decided about their food and beverage consumption. Two predictions summarize the conflicting views on the role of limited willpower in obesity. If technical "progress" in producing fatty food is indeed a major driving force behind obesity, the standard economic model predicts that individuals will become heavier and happier. However, if individuals have self-control problems, we would expect them to become heavier and less happy.

\footnotetext{
${ }^{17}$ This argumentation on the revealed preference approach does not exclude that observed behavior can give clear indications of a problem with the control of body mass, e.g., when people inflict costs on themselves in order to make eating chocolate less attractive. However, the revealed preference approach gives no reason to search for such contradictory patterns in consumption behavior. On the contrary, it urges the researcher to look for rationalizations.

${ }^{18}$ With regard to obesity, the self-control issue is explicitly addressed in Cutler et al. (2003), whereby its relevance in the assessment of consumers' welfare is discounted because it would require only some exercise on the part of overweight people to balance their energy household. Observed inactivity thus seems to indicate that overweight people do not suffer from their body mass. However, the tradeoff is calculated, assuming that people have self-control problems with eating, but not with taking physical exercise. This asymmetry does not fit our casual observations.
} 
There is a growing literature on empirical research, studying whether obese people are less satisfied. According to an empirical investigation for roughly 8,000 young women, obesity is related to lower satisfaction with work, family relationships, partner relationship and social activities (but not satisfaction with friendships) (Ball et al. 2004). Other studies report correlations between obesity and symptoms of depression, whereby the risk of depression is higher for obese women than obese men (e.g. McElroy et al. 2004; Needham and Crosnoe 2005). These findings, however, provide only limited insights, as the correlations can be due to third variables affecting both eating behavior and subjective well-being, or because low life satisfaction and stress can lead to obesity. The latter has been studied in a longitudinal analysis for 5,867 pairs of twins (Korkeila et al. 1998). It is found that a high level of stress, as well as a low level of life satisfaction, are both predictors of weight gain over six years and for certain groups of people over 15 years of age. Another panel study addresses the reverse relationship. Taking baseline mental health into account, it analyzes the long term consequences of obesity, finding an increased risk for depression (Roberts et al. 2002). These results are valuable to assess the relevance of the phenomenon, but they have to be supplemented with further evidence to identify the contribution of self-control problems to the link between obesity and subjective well-being.

Alternatively, it is possible to characterize conditions where attempts to recapture self-control are encouraged. It is to be expected that those people who stand to lose a lot from being obese, or who have access to resources, are more successful in controlling their behavior. For example, obese women seem to suffer a salary and promotion penalty even more than obese men (see, e.g., Baum and Ford 2004, Finkelstein et al. 2005). They have strong incentives to control their body weight and might suffer more when their lack of willpower leads to failure. Consistent with this point of view, people in the top income quintile, or in professions with a low prevalence of obesity, report the largest well-being costs of obesity (Felton and Graham 2005). People with a higher education or income level are more likely to view themselves as overweight, keeping the level of the BMI constant (Oswald and Powdthavee 2007).

\subsection{Willpower, obesity and subjective well-being}

\section{Hypothesis and data}

Based on the preceding subsection, it is hypothesized that the well-being of people with limited self-control is reduced when they are obese, while the well-being of people with strong willpower is not affected. This hypothesis follows the general testing strategy proposed 
in section II.B in order to better understand suboptimal consumption decisions. Here an empirical analysis is presented based on a unique data set combining information on people's weight, height, perceived control over their life and eating behavior, as well as a multi-item measure of subjective well-being. The original analysis is developed and described in detail in Stutzer (2007).

The data is from the Swiss Health Survey 2002 compiled by the Swiss Federal Statistical Office. It combines responses from a telephone survey and a questionnaire mailing going to the same people. The sampling population was the resident population aged 15 and over. 19,706 individuals were interviewed and 16,141 of them responded to a supplementary written questionnaire. For 19,471 respondents there is complete information about their body mass. Based on a weighted distribution of the BMI index, the percentage of obese people in the adult population amounted to $7.7 \%$ in 2002 , an increase of 2.3 percentage points since 1992. $29.4 \%$ are overweight and $49.9 \%$ normal weight. There is also a substantial fraction of 13.0\% having a BMI below 20 and thus being underweight. People's subjective well-being is assessed using eight questions from the Bern Questionnaire of Subjective Well-Being (Grob et al. 1991). The questions are reported in the appendix. The main analysis is for the compound measure based on the eight items. Variation in self-control between people is assessed using a general measure of reported mastery and a specific measure of reported willpower in pursuing a healthy diet. The mastery scale is from Pearlin et al. (1981), whereby 4 out of 7 questions were included in the survey (see appendix). In the analyzed sample, $24.1 \%$ of the subjects report that they feel in control of their life, i.e. all questions of limited mastery are completely denied. Domain specific willpower is derived from the following survey item: "Many people - maybe you too - attach importance to a healthy diet. Do you see obstacles for somebody who pursues a healthy diet? Please tick all reasons that apply! ... 'lack of willpower, lack of belief in success'." Limited willpower with regard to a healthy diet is reported by $25.5 \%$ of people in the sample.

\section{Results}

People's body mass is compared to their subjective well-being. ${ }^{19}$ According to the basic hypothesis, obesity is expected to negatively affect the subjective well-being of those with

\footnotetext{
${ }^{19}$ Stutzer (2007) also studies the covariates of body mass in a multinomial regression analysis. In addition to standard demographic and socio-economic factors, indicators of ignorance and limited willpower are included. It is found that people who report that health is not a relevant issue for them are statistically significantly more likely to be obese than people who report that health is either
} 
limited willpower. For them, obesity is not meant to be the outcome of rational food consumption but rather of time inconsistent behavior. The dependent variable "reported subjective well-being" is now an ordinal measure. Ordered probit regressions are estimated and marginal effects are calculated for the top category of subjective well-being. For dummy variables, the marginal effects indicate a change in the probability of reporting high subjective well-being. In table 1, results for two different specifications are presented. Specification I includes people's body mass, dividing it into four categories, as well as categorizations of their age and sex. This specification assures that no other choice variables pick up any potential negative consequence of obesity on well-being. Specification II includes a large set of covariates of subjective well-being. The Swiss Health Survey provides sufficient information about individual characteristics to specify a microeconometric well-being function, that is similar to the ones usually applied when testing economic issues. Table A.1 in the appendix presents the results for such a specification, including all the control variables and covering the full sample. They confirm previous findings in the literature on the correlates of happiness. The findings for the BMI are also shown in the lower half of the first column in table 1.

\section{[Table 1 about here]}

In both equations with the full sample, obesity is negatively correlated with subjective wellbeing. However, the partial correlation is not statistically significant in specification II. Moreover, the partial correlations are not yet a test of the theoretical prediction. A very high BMI is hypothesized to negatively affect well-being if it is the result of limited self-control, but not otherwise. Therefore, the partial correlation between obesity and subjective well-being are estimated separately for people with full and limited self-control. Both indicators of selfcontrol are applied: mastery and domain specific willpower.

With two specifications each, results from eight estimations are summarized in Table 1. Consistent with the basic hypothesis, obesity is related with lower subjective well-being when people have limited self-control but no statistically significant effect is found for the sample of people classified as having full self-control. The marginal effect is largest with specification I for the sample of people who report a lack of willpower as being an obstacle to

relevant or very important for them. The relative risk ratio indicates a 1.51 greater probability. Consistent with this, people who care about their diet are less likely to be obese, with a risk ratio of 0.81 relative to people who do not care. Moreover, people who report a lack of willpower when it comes to a healthy diet have a higher probability of being obese, the relative risk ratio being 1.41. 
a healthy diet. The probability of reporting high subjective well-being is 3.4 percentage points lower for people who are obese rather than normal weight, whereby the baseline probability for people in the reference group is 8.6 percent.

Together, the pieces of evidence from the study of people's subjective well-being indicate that the phenomenon of obesity can only be understood when going beyond revealed preference and the assumption of unlimited consumer sovereignty, but taking limited willpower into account.

\subsection{Three open issues}

The general approach proposed in this paper to study the effect of limited willpower on individual welfare raises three related issues that we have not yet taken up. These are the generalization of self-control behavior, reverse causality, and the distinction between outcome and process as possible reasons for reduced well-being when somebody is a heavy TV viewer, a smoker or obese. The three issues are again discussed for the case of obesity.

The first issue has to do with the nature of limited willpower. People are exposed to many opportunities, with low immediate marginal costs, but high marginal benefits. The question arises whether people with a self-control problem make myopic decisions when faced with all, or most, of these opportunities, or whether they are able to control some challenges to willpower, but find it too difficult to control all of them. The latter view fits in with the idea that there is a limited capacity for self-regulation. Resisting one temptation may result in poorer regulation of a concurrent desire for immediate gratification, or vice versa (Muraven et al. 1998).

For the identification of limited willpower in the proposed approach, it has to be assumed that either self-control behavior generalizes across-the-board or tempting activities that are close substitutes have to be taken into account statistically. ${ }^{20}$ The idea that self-control resembles a muscle might be particularly relevant in understanding the interplay between obesity and smoking (Gruber and Frakes 2006). People who work at controlling their eating habits might give up on resisting smoking and vice versa. In the presented study by Stutzer (2007) on the negative effect of obesity, information about whether somebody is a smoker or non-smoker is also included. For the main specification II, with the specific indicator of self-control, almost

\footnotetext{
${ }^{20}$ This condition can also explain why a domain specific indicator of willpower is a better predictor of obesity and reduced well-being of obese people than a general indicator of perceived control.
} 
identical marginal effects as before are found. For people with limited self-control, the marginal effect of obesity is $-0.026(-0.027$ before $)$. For people with full self-control, the marginal effect of obesity is 0.005 (0.005 before). The main result is thus robust to the inclusion of the closest substitute to yielding to the temptation to overconsume.

The second issue concerns causality. To what extent do the consequences of obesity due to limited willpower reduce subjective well-being and to what extent does the experience of reduced well-being lead to stress/frustration eating and obesity? This is a valid concern, even though based on the approach proposed in this paper the correlation between obesity and subjective well-being is not interpreted as such, but rather the differential effect for people with full and limited self-control. The data set used in Stutzer (2007) captures whether somebody turns to eating when stressed. Stress eating is found to negatively correlate with subjective well-being in the full sample, keeping body mass constant. Moreover, the marginal effects are sizeable. While the baseline probability of people reporting subjective well-being in the top category is 8.4 percent, this probability is reduced by between 1.7 and 3.7 percentage points if stress eating is not 'very untypical' but is either 'rather untypical' or 'very typical'. However, the differential effect of obesity on subjective well-being between people with limited and full self-control is not explained by stress eating. For the general indicator of self-control, the difference in the marginal effects of obesity on individual wellbeing is slightly larger when comparing people with limited and full self-control. For the specifications applying the specific indicator of self-control, the difference in marginal effects is slightly reduced. However, people who lack the willpower to stick to a healthy diet still report a significantly lower subjective well-being when they are obese (marginal effect $=-2.0$ percentage points), while there is no such negative effect for people who report full selfcontrol. A direct test for reverse causation thus cannot explain the reduced well-being of obese people in the case of limited willpower.

The third question is whether reduced willpower as such, rather than its consequences, is responsible for lower well-being. Limited willpower might well repeatedly lead to experiencing frustration because plans regarding one's diet are not realized. People who experience self-control problems then suffer reduced self-esteem, and thus lower subjective well-being. Related empirical evidence is found in a community sample of 2,000 adults (Greeno et al. 1998). In addition to a higher BMI, the lack of perceived eating control was associated with lower satisfaction with life. For men, it was only the lack of eating control that was correlated with reported subjective well-being. This line of reasoning is important in 
order to understand the relationship between appearance norms, body image and eating disorders (Derenne and Beresin 2006). In the analysis presented above, this aspect is not studied directly. However, the effect of limited willpower on the level of people's well-being is statistically taken into account when estimating separate equations as it enters into the constant term.

\section{Concluding Remarks}

This chapter has started out with the provocative question on how to judge whether people make suboptimal consumption choices according to their own evaluation. Within standard neoclassical economics this issue would not have been raised. Standard economic theory assumes that individuals do not commit any systematic errors in their consumption decisions, because they know their own preferences best and are able to make and implement the consequent choices. Limited willpower is no concern. No doubt, it is very likely that individuals are quite capable of making satisfactory consumption decisions for most of the goods most of the time.

The main message of this chapter is that it is necessary to go beyond this narrow approach. One should take into account the methodological advances made possible by happiness research. They allow us to empirically test whether individuals do or do not make suboptimal decisions due to limited willpower, rather than simply assuming that they do not, as is the case in revealed preference theory. The possibility to proxy individual welfare in a satisfactory way using data on reported subjective well-being enables economists to empirically study the difference between decisions made and the individual welfare produced. We see a large potential in this approach to study many areas of consumption choice for which popular discourse and most other disciplines acknowledge people's difficulties in the pursuit of happiness.

The proposed approach, however, also requires particular transparency as every empirical analysis gives priority to a specific measure of subjective well-being as a criterion of individual welfare. This involves a strong normative judgment. We are aware that different indicators of individual welfare potentially offer different evaluations of what are suboptimal decisions. They thus capture different aspects of people's pursuit of happiness. For example, people might gain utility from exerting willpower because they have resisted a temptation. Or, they judge their life favorably because their life course contributes to positive self-signaling, 
identity, goal completion, mastery or meaning (for economic analyses of these human motives see, e.g., Akerlof and Kranton 2000 and Loewenstein 1999).

When thinking about policy proposals, it is important to know whether and to what extent people face a self-control problem when tempted by the abundance of consumption opportunities. For instance, take the abundance of food and the observed obesity. Is obesity rational and reflecting an appetite for food so that it can be reduced to an issue of externalities in a publicly regulated and funded health system? Or does it reflect ignorance and a lack of imagination of its consequences, requiring some sort of information policy? Or must obesity be treated like smoking, where some people lack willpower to control their behavior? The challenge for research is to disentangle the various behavioral reasons for obesity. But even if these questions can be answered for the three specific areas discussed, the suboptimal consumption patterns due to limited willpower are no cause for immediate government intervention. Moreover, it is doubtful whether "the government" is able to make better decisions in the interests of the persons concerned (see Frey and Stutzer 2006). It is presumably more effective to support individuals subject to self-control problems by providing ways of overcoming their weakness, for example by proposing self-binding mechanisms (for a broader discussion see, e.g., O'Donoghue and Rabin 2005).

It should thus be clear that this analysis is not a normative evaluation from the point of view of a benevolent social planner. Rather, the focus is on the suboptimal choices in consumption that individuals commit according to their own perception, placing people in a less favorable position in terms of their own welfare evaluation. Thus the policy goal remains a search for institutions under which suboptimal choices are less likely and people are better off accepting their limited willpower. 


\section{Appendix}

\section{Scales applied in the Swiss Health Survey and studied in Stutzer (2007)}

Subjective well-being (translated from Grob et al. 1991)

To what extent do the following statements apply to you?

- My future looks bright.

- I enjoy life more than most people.

- I am satisfied with how my life plans materialize.

- I deal well with those things in my life that cannot be changed.

- Whatever happens, I make the best out of it.

- I enjoy my life.

- My life is meaningful to me.

- My life is on the right track.

Possible answers: 1=completely wrong, 2=very wrong, 3=rather wrong, 4=rather accurate, $5=$ very accurate, $6=$ completely accurate.

The responses are added together (SWB_tot) and summarized on a six point scale according to the following criteria:

SWB_tot $>=44 \&$ SWB_tot $<=48 \rightarrow$ SWB $=6$

SWB tot $>=40 \& \mathrm{SWB}$ tot $<44 \rightarrow \mathrm{SWB}=5$

$\mathrm{SWB}$ tot $>=36 \& \mathrm{SWB}$ tot $<40 \rightarrow \mathrm{SWB}=4$

SWB_tot $>=32 \& \mathrm{SWB}$ - tot $<36 \rightarrow \mathrm{SWB}=3$

SWB_tot $>=28 \& \mathrm{SWB}$ tot $<32 \rightarrow \mathrm{SWB}=2$

SWB_tot $>=8 \& \mathrm{SWB}$ tot $<28 \rightarrow \mathrm{SWB}=1$

Mastery (based on 4 out of 7 questions from Pearlin et al. 1981)

When you think about your life, how strongly do you agree or disagree with these statements about yourself?

- There is really no way I can solve some of the problems I have.

- Sometimes I feel that I'm being pushed around in life.

- I have little control over the things that happen to me.

- I often feel helpless in dealing with the problems of life.

Possible responses: completely agree, rather agree, rather disagree, completely disagree. 
Table A.1. Covariates of Subjective Well-Being in Switzerland, 2002

\begin{tabular}{|c|c|c|c|c|c|c|}
\hline & \multicolumn{6}{|c|}{ Ordered probit regression } \\
\hline & \multicolumn{2}{|c|}{ Coefficient } & \multirow[t]{2}{*}{ z-value } & \multicolumn{2}{|c|}{$\begin{array}{l}\text { Marginal effect for } \\
\quad \text { a score of } 6\end{array}$} & z-value \\
\hline \multicolumn{6}{|l|}{ BMI } & \\
\hline Underweight & -0.053 & $(*)$ & -1.91 & -0.008 & $(*)$ & -1.96 \\
\hline Normal weight & \multicolumn{6}{|c|}{ Reference group } \\
\hline Overweight & -0.022 & & -1.08 & -0.004 & & -1.09 \\
\hline Obese & -0.047 & & -1.42 & -0.008 & & -1.46 \\
\hline \multicolumn{7}{|l|}{ Demographic factors } \\
\hline Age $15-19$ & 0.125 & $(*)$ & 1.74 & 0.022 & & 1.62 \\
\hline Age $20-24$ & 0.293 & $* *$ & 5.04 & 0.058 & $* *$ & 4.33 \\
\hline Age $25-29$ & 0.195 & $* *$ & 4.39 & 0.036 & $* *$ & 3.96 \\
\hline Age $30-34$ & 0.120 & $* *$ & 3.35 & 0.021 & $* *$ & 3.15 \\
\hline Age $35-39$ & \multicolumn{6}{|c|}{ Reference group } \\
\hline Age $40-44$ & -0.064 & $(*)$ & -1.78 & -0.010 & $(*)$ & -1.84 \\
\hline Age $45-49$ & -0.040 & & -1.01 & -0.006 & & -1.03 \\
\hline Age $50-54$ & -0.037 & & -0.88 & -0.006 & & -0.90 \\
\hline Age $55-59$ & 0.034 & & 0.83 & 0.006 & & 0.82 \\
\hline Age $60-64$ & 0.135 & $* *$ & 3.04 & 0.024 & $* *$ & 2.83 \\
\hline Age $65-69$ & 0.353 & $* *$ & 5.86 & 0.071 & $* *$ & 4.96 \\
\hline Age $70-74$ & 0.357 & $* *$ & 5.39 & 0.072 & $* *$ & 4.53 \\
\hline Age $75-79$ & 0.405 & $* *$ & 5.74 & 0.084 & $* *$ & 4.73 \\
\hline Age 80 and older & 0.525 & $* *$ & 6.68 & 0.117 & $* *$ & 5.27 \\
\hline Female & 0.086 & $* *$ & 4.11 & 0.014 & $* *$ & 4.12 \\
\hline \multicolumn{7}{|l|}{ Level of education } \\
\hline Mandatory schooling & \multicolumn{6}{|c|}{ Reference group } \\
\hline Secondary general edu. & -0.047 & & -1.09 & -0.008 & & -1.12 \\
\hline Secondary prof. education & 0.030 & & 1.07 & 0.005 & & 1.07 \\
\hline Tertiary professional edu. & 0.104 & $* *$ & 2.71 & 0.018 & $*$ & 2.57 \\
\hline University & 0.021 & & 0.50 & 0.004 & & 0.49 \\
\hline \multicolumn{7}{|l|}{ Marital status } \\
\hline Married & \multicolumn{6}{|c|}{ Reference group } \\
\hline Single & -0.214 & $* *$ & -6.37 & -0.033 & $* *$ & -6.78 \\
\hline Widowed & -0.077 & $(*)$ & -1.76 & -0.012 & $(*)$ & -1.84 \\
\hline Divorced & -0.113 & $* *$ & -3.02 & -0.018 & $* *$ & -3.22 \\
\hline Separated & -0.238 & $* *$ & -3.18 & -0.034 & $* *$ & -3.78 \\
\hline \multicolumn{7}{|l|}{ Household composition } \\
\hline 1 adult & \multicolumn{6}{|c|}{ Reference group } \\
\hline 2 adults & 0.098 & $* *$ & 3.28 & 0.016 & $* *$ & 3.29 \\
\hline 3 adults & 0.095 & $*$ & 2.40 & 0.016 & $*$ & 2.28 \\
\hline 4 adults and more & 0.182 & $* *$ & 3.97 & 0.033 & $* *$ & 3.61 \\
\hline No children & \multicolumn{6}{|c|}{ Reference group } \\
\hline 1 child & 0.049 & & 1.55 & 0.008 & & 1.51 \\
\hline 2 children & 0.063 & $(*)$ & 1.83 & 0.011 & $(*)$ & 1.78 \\
\hline 3 children and more & 0.123 & $*$ & 2.53 & 0.022 & $*$ & 2.36 \\
\hline \multicolumn{7}{|l|}{ Citizenship status } \\
\hline Foreigner & -0.119 & $* *$ & -4.06 & -0.018 & $* *$ & -4.33 \\
\hline \multicolumn{7}{|l|}{ Main life circumstances } \\
\hline Full-time job & & & & e group & & \\
\hline Part-time job & -0.059 & $*$ & -2.56 & -0.010 & $* *$ & -2.62 \\
\hline Family business & 0.121 & & 1.04 & 0.022 & & 0.97 \\
\hline In education & -0.004 & & -0.08 & -0.001 & & -0.08 \\
\hline Unemployed & -0.367 & $* *$ & -5.46 & -0.048 & $* *$ & -7.20 \\
\hline Housework & -0.027 & & -1.02 & -0.004 & & -1.03 \\
\hline Retired & -0.182 & $* *$ & -3.46 & -0.028 & $* *$ & -3.75 \\
\hline Chronically ill & -0.578 & $* *$ & -9.23 & -0.065 & $* *$ & -14.40 \\
\hline
\end{tabular}


Income

Ln(equivalence income)

$1.415 * * \quad 8.43$

0.422

6.56

No. of obs.

15108

Pseudo $\mathrm{R}^{2}$

0.021

Notes: Ordered probit regression. Further control variables not shown are 'education not defined', 'other paid activity', 'other life circumstances', 'income not available', 'interview in French', 'interview in Italian'.

Significance levels: $(*) .05<\mathrm{p}<.1, * .01<\mathrm{p}<.05, * * \mathrm{p}<.01$.

Data source: Stutzer (2007) based on Swiss Health Survey 2002. 


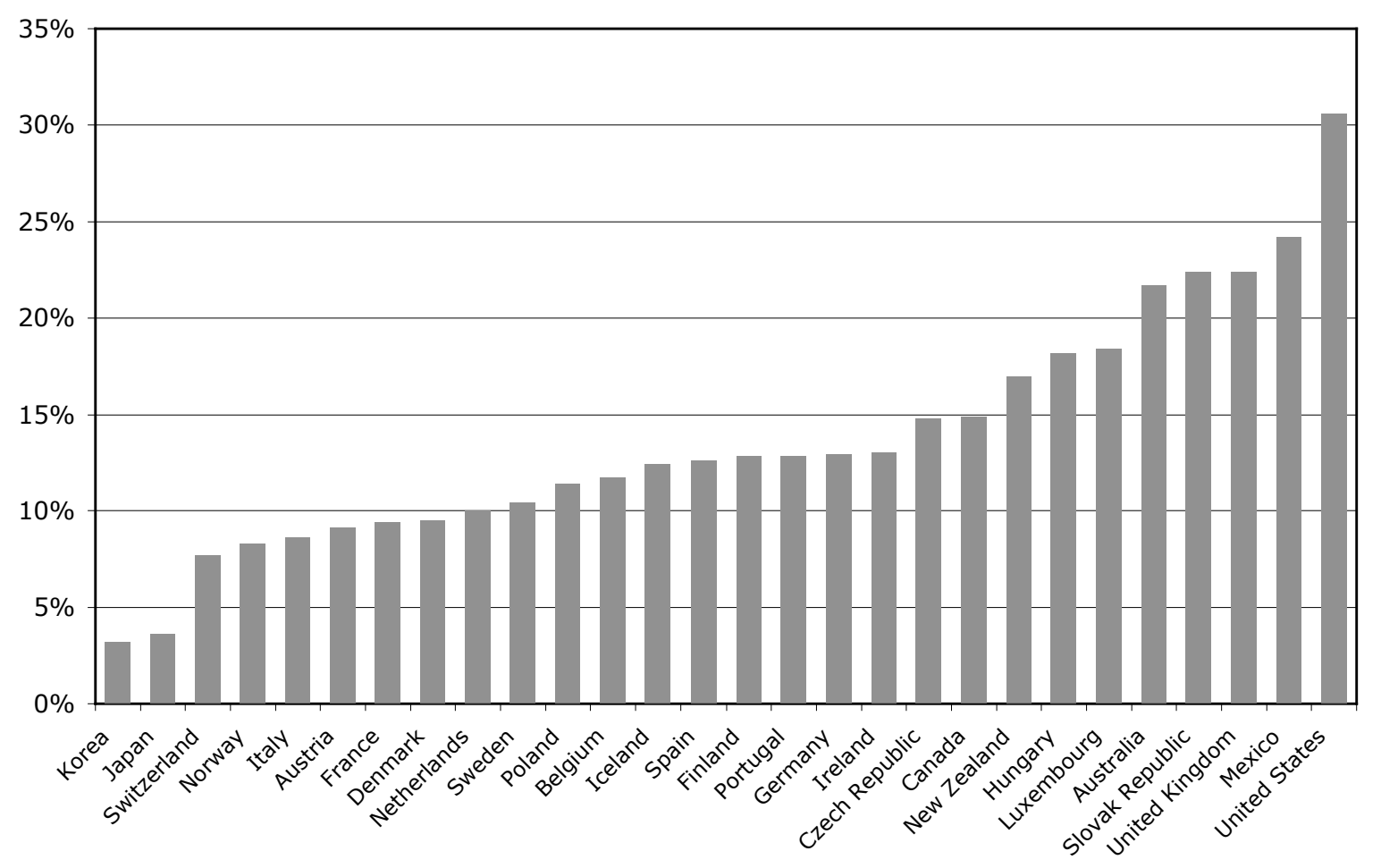

Figure 1. Obesity across countries

Note: Percentage of population aged 15 and over, with a BMI greater than 30 (2003 or latest available year).

Source: OECD Factbook 2005. 
Table 1. BMI and Reported Subjective Well-Being

\begin{tabular}{|c|c|c|c|c|c|}
\hline & Full sample & \multicolumn{2}{|c|}{$\begin{array}{c}\text { General indicator of self-control: } \\
\text { Mastery }\end{array}$} & \multicolumn{2}{|c|}{$\begin{array}{c}\text { Specific indicator of self-control } \\
\text { Lack of willpower is an obstacle } \\
\text { to a healthy diet }\end{array}$} \\
\hline & & $\begin{array}{l}\text { limited } \\
\text { self-control }\end{array}$ & $\begin{array}{l}\text { full } \\
\text { self-control }\end{array}$ & $\begin{array}{l}\text { limited } \\
\text { self-control }\end{array}$ & $\begin{array}{l}\text { full } \\
\text { self-control }\end{array}$ \\
\hline & \multicolumn{5}{|c|}{ Marginal effects for the top category of SWB } \\
\hline $\begin{array}{l}\text { Specification I } \\
\text { Underweight }\end{array}$ & $\begin{array}{rl}-0.012 & * * \\
(4.43 \mathrm{e}-3) & \end{array}$ & $\begin{array}{r}-0.010 * * \\
(3.13 \mathrm{e}-3)\end{array}$ & $\begin{array}{r}0.029 \\
(2.05 \mathrm{e}-2)\end{array}$ & $\begin{array}{r}-0.012 \\
(8.18 \mathrm{e}-3)\end{array}$ & $\begin{array}{r}-0.011 * \\
(5.39 \mathrm{e}-3)\end{array}$ \\
\hline Normal weight & & Refer & e group & & \\
\hline Overweight & $\begin{array}{r}-0.003 \\
(3.46 \mathrm{e}-3)\end{array}$ & $\begin{array}{r}-0.001 \\
(2.66 \mathrm{e}-3)\end{array}$ & $\begin{array}{r}-0.018 \\
(1.26 \mathrm{e}-2)\end{array}$ & $\begin{array}{r}-0.010 \\
(6.46 \mathrm{e}-3)\end{array}$ & $\begin{array}{r}-0.001 \\
(4.18 \mathrm{e}-3)\end{array}$ \\
\hline Obese & $\begin{array}{rl}-0.014 & * * \\
(5.16 \mathrm{e}-3) & \end{array}$ & $\begin{array}{r}-0.012 * * \\
(3.76 \mathrm{e}-3)\end{array}$ & $\begin{array}{r}-0.003 \\
(2.09 \mathrm{e}-2)\end{array}$ & $\begin{array}{r}-0.034 * * \\
(7.63 \mathrm{e}-3)\end{array}$ & $\begin{array}{r}-0.002 \\
(6.83 \mathrm{e}-3)\end{array}$ \\
\hline Control variables & & Age categorie & nd sex included & & \\
\hline Baseline prob. & 0.099 & 0.055 & 0.230 & 0.086 & 0.097 \\
\hline $\begin{array}{l}\text { No. of obs. } \\
\text { Pseudo } \mathrm{R}^{2}\end{array}$ & $\begin{array}{r}15108 \\
0.002\end{array}$ & $\begin{array}{r}10681 \\
0.002\end{array}$ & $\begin{array}{r}3392 \\
0.004\end{array}$ & $\begin{array}{r}3458 \\
0.003\end{array}$ & $\begin{array}{r}10117 \\
0.002\end{array}$ \\
\hline $\begin{array}{l}\text { Specification II } \\
\text { Underweight }\end{array}$ & $\begin{array}{r}-0.008 \quad(*) \\
(4.32 \mathrm{e}-3)\end{array}$ & $\begin{array}{r}-0.007 * \\
(3.01 \mathrm{e}-3)\end{array}$ & $\begin{array}{r}0.028 \\
(2.04 \mathrm{e}-2)\end{array}$ & $\begin{array}{r}-0.010 \\
(7.71 \mathrm{e}-3)\end{array}$ & $\begin{array}{r}-0.006 \\
(5.31 \mathrm{e}-3)\end{array}$ \\
\hline Normal weight & & Refer & e group & & \\
\hline Overweight & $\begin{array}{r}-0.004 \\
(3.32 \mathrm{e}-3)\end{array}$ & $\begin{array}{r}-0.002 \\
(2.49 \mathrm{e}-3)\end{array}$ & $\begin{array}{r}-0.012 \\
(1.26 \mathrm{e}-2)\end{array}$ & $\begin{aligned}-0.010 \quad(*) \\
(6.07 \mathrm{e}-3)\end{aligned}$ & $\begin{array}{r}-0.002 \\
(4.01 \mathrm{e}-3)\end{array}$ \\
\hline Obese & $\begin{array}{r}-0.008 \\
(5.17 \mathrm{e}-3)\end{array}$ & $\begin{array}{r}-0.008 * \\
(3.69 \mathrm{e}-3)\end{array}$ & $\begin{array}{r}0.013 \\
(2.15 \mathrm{e}-2)\end{array}$ & $\begin{array}{r}-0.027 * * \\
(7.49 \mathrm{e}-3)\end{array}$ & $\begin{array}{r}0.005 \\
(6.88 \mathrm{e}-3)\end{array}$ \\
\hline Control variables & & $\begin{array}{l}\text { All fact } \\
\text { (see ap }\end{array}$ & $\begin{array}{l}\text { included } \\
\text { adix A.1) }\end{array}$ & & \\
\hline Baseline prob. & 0.092 & 0.050 & 0.225 & 0.078 & 0.090 \\
\hline No. of obs. & 15108 & 10681 & 3392 & 3458 & 10117 \\
\hline Pseudo $\mathrm{R}^{2}$ & 0.021 & 0.021 & 0.019 & 0.027 & 0.021 \\
\hline
\end{tabular}

Notes: Marginal effects based on ordered probit regression. Standard errors in parentheses. Significance levels: $(*) .05<\mathrm{p}<.1, * .01<\mathrm{p}<.05, * * \mathrm{p}<.01$.

Data source: Stutzer (2007) based on Swiss Health Survey 2002. 


\section{References}

Akerlof, George A. and Rachel E. Kranton (2000). Economics and Identity. Quarterly Journal of Economics 115(3): 715-53.

Ameriks, John, Andrew Caplin, John Leahy and Tom Tyler (2007). Measuring Self Control Problems. Forthcoming in American Economic Review.

Ball, Kylie, David Crawford and Justin Kenardy (2004). Longitudinal Relationships among Overweight, Life Satisfaction, and Aspirations in Young Women. Obesity Research 12(6): 1019-1030.

Baum, Charles L., II and William F. Ford (2004). The Wage Effects of Obesity: A Longitudinal Study. Health Economics 13(9): 885-899.

Becker, Lee B. and Klaus Schoenbach (eds.) (1989). Audience Responses to Media Diversification: Coping with Plenty. Hillsdale, NJ: Lawrence Erlbaum Associates.

Benesch, Christine, Bruno S. Frey and Alois Stutzer (2006). TV Channels, Self Control and Happiness. IEW Working Paper No. 301, University of Zurich.

Bernheim, Douglas and Antonio Rangel (2004). Addiction and Cue-Triggered Decision Processes. American Economic Review 94(5): 1558-1590.

Bernheim, B. Douglas and Antonio Rangel (2007). Toward Choice-Theoretic Foundations for Behavioral Welfare Economics. American Economic Review 97(2): 464-470.

Blundell, John E. and Angela Gillett (2001). Control of Food Intake in the Obese. Obesity Research 9 (Suppl. 4): 263S-270S.

Borghans, Lex and Bart H. H. Golsteyn (2006). Time Discounting and the Body Mass Index, Evidence from the Netherlands. Economics and Human Biology 4(1): 39-61.

Bruni, Luigino and Luca Stanca (2006). Income Aspirations, Television and Happiness: Evidence from the World Values Survey. Kyklos 59(2): 209-225.

Bruni, Luigino and Luca Stanca (2007). Watching Alone: Relational Goods, Television and Happiness. Journal of Economic Behavior \& Organization, forthcoming.

Camerer, Colin, George Loewenstein and Matthew Rabin (eds.) (2004). Advances in Behavioral Economics. New York: Russell Sage Foundation.

Corneo, Giacomo (2005). Work and Television. European Journal of Political Economy 21(1): 99-113.

Csikszentmihalyi, Mihaly and Jeremy Hunter (2003). Happiness in Everyday Life: The Uses of Experience Sampling. Journal of Happiness Studies 4(2): 185-199.

Cutler, David M., Edward L. Glaeser and Jesse M. Shapiro (2003). Why Have Americans Become More Obese? Journal of Economic Perspectives 17(3): 93-118.

De Cremer, David, Marcel Zeelenberg and J. Keith Murnighan (eds.) (2006). Social Psychology and Economics. Mahwah, N.J.: Lawrence Erlbaum.

DellaVigna, Stefano and M. Daniele Paserman (2005). Job Search and Impatience. Journal of Labor Economics 23(3): 527-588.

Derenne, Jennifer L. and Eugene V. Beresin (2006). Body Image, Media, and Eating Disorders. Academic Psychiatry 30(3): 257-261.

Felton, Andrew and Carol Graham (2005). Variance in Obesity across Cohorts and Countries: A Norms-Based Explanation Using Happiness Surveys. Mimeo, The Brookings Institution. 
Finkelstein, Eric A., Christopher J. Ruhm and Katherine M. Kosa (2005). Economic Causes and Consequences of Obesity. Annual Review of Public Health 26: 239-257.

Flegal, Katherine M., Margaret D. Carroll, Cynthia L. Ogden and Clifford L. Johnson (2002). Prevalence and Trends in Obesity among US Adults, 1999-2000. JAMA 288(14): 17231727.

Frederick, Shane, George Loewenstein and Ted O'Donoghue (2002). Time Discounting and Time Preference: A Critical Review. Journal of Economic Literature 40(2): 351-401.

Frey, Bruno S. (2008). Happiness: A Revolution in Economics. Cambridge, MA: MIT Press.

Frey, Bruno S., Christine Benesch and Alois Stutzer (2007). Does Watching TV Make Us Happy? Journal of Economic Psychology 28(3): 283-313.

Frey, Bruno S. and Alois Stutzer (2002a). Happiness and Economics: How the Economy and Institutions Affect Well-Being. Princeton and Oxford: Princeton University Press.

Frey, Bruno S. and Alois Stutzer (2002b). What Can Economists Learn from Happiness Research? Journal of Economic Literature 40(2): 402-435.

Frey, Bruno S. and Alois Stutzer (2005). Testing Theories of Happiness. In: Luigino Bruni and Pier Luigi Porta (eds.). Economics and Happiness. Framing the Analysis. Oxford: Oxford University Press: 116-146.

Frey, Bruno S. and Alois Stutzer (2006). Mispredicting Utility and the Political Process. In: Edward J. McCaffery and Joel Slemrod (eds.). Behavioral Public Finance. New York: Russell Sage Foundation: 113-140.

Frey, Bruno S. and Alois Stutzer (eds.) (2007). Economics and Psychology. A Promising New Cross-Disciplinary Field. Cambridge, MA: MIT Press.

Gentzkow, Matthew (2006). Television and Voter Turnout. Quarterly Journal of Economics 121(3): 931-972.

Greeno, Catherine G., Christine Jackson, Elizabeth L. Williams and Stephen P. Fortmann (1998). The Effect of Perceived Control over Eating on the Life Satisfaction of Women and Men: Results from a Community Sample. International Journal of Eating Disorders 24(4): 415-419.

Grob, Alexander, Ruth Luthi, Florian G. Kaiser and August Flammer (1991). Berner Fragebogen zum Wohlbefinden Jugendlicher (Bfw) The Bern Subjective Well-Being Questionnaire for Adolescents (Bfw). Diagnostica 37(1): 66-75.

Gruber, Jonathan H. and Michael Frakes (2006). Does Falling Smoking Lead to Rising Obesity? Journal of Health Economics 25(2): 183-197.

Gruber, Jonathan H. and Botond Koszegi (2001). Is Addiction "Rational"? Theory and Evidence. Quarterly Journal of Economics 116(4): 1261-1303.

Gruber, Jonathan H. and Sendhil Mullainathan (2005). Do Cigarette Taxes Make Smokers Happier? Advances in Economic Analysis and Policy 5(1): 1-43.

Gul, Faruk and Wolfgang Pesendorfer (2007). Welfare without Happiness. American Economic Review 97(2): 471-476.

Helliwell, John F. (2006). Well-Being, Social Capital and Public Policy: What's New? Economic Journal 116(510): C34-C45.

Hennigan, Karen M., Linda Heath, J. D. Wharton, M. L. Delrosario, T. D. Cook and B. J. Calder (1982). Impact of the Introduction of Television on Crime in the United-States: Empirical-Findings and Theoretical Implications. Journal of Personality and Social Psychology 42(3): 461-477. 
Hersch, Joni (2005). Smoking Restrictions as a Self-Control Mechanism. Journal of Risk and Uncertainty 31(1): 5-21.

Hsee, Christopher K., Yuval Rottenstreich and Alois Stutzer (2008). Suboptimal Choices and the Need for Experienced Individual Well-Being in Economic Analysis. Mimeo, University of Basel.

John, Oliver P. and Sanjay Srivastava (1999). The Big Five Trait Taxonomy: History, Measurement, and Theoretical Perspectives. In: Lawrence A. Pervin and Oliver P. John (eds.). Handbook of Personality: Theory and Research. New York: Guilford Press: 102138.

Jürges, Hendrik (2004). The Welfare Costs of Addiction. Schmollers Jahrbuch 124(3): 327353.

Kahneman, Daniel and Jason Riis (2005). Living, and thinking about it: Two perspectives on life. In: Felicia A. Huppert, Nick Baylis and Barry Keverne (eds.). The Science of Well Being. Oxford: Oxford University Press.

Kahneman, Daniel, Alan B. Krueger, David A. Schkade, Norbert Schwarz and Arthur A. Stone (2004). A Survey Method for Characterizing Daily Life Experience: The Day Reconstruction Method. Science 306(5702): 1776-1780.

Kahneman, Daniel, Ed Diener and Norbert Schwarz (eds.) (1999). Well-Being: The Foundations of Hedonic Psychology. New York, NY: Russell Sage Foundation.

Kahneman, Daniel, Jack L. Knetsch and Richard H. Thaler (1991). The Endowment Effect, Loss Aversion, and Status Quo Bias: Anomalies. Journal of Economic Perspectives 5(1): 193-206.

Kasser, Tim (2002). The High Price of Materialism. Cambridge, MA: MIT Press.

Kelman, Mark (2005). Hedonic Psychology and the Ambiguities of "Welfare". Philosophy and Public Affairs 33(4): 391-412.

Komlos, John, Patricia K. Smith and Barry Bogin (2004). Obesity and the Rate of Time Preference: Is There a Connection? Journal of Biosocial Science 36(2): 209-219.

Korkeila, M., J. Kaprio, A. Rissanen, M. Koskenvuo and T. I. A. Sorensen (1998). Predictors of Major Weight Gain in Adult Finns: Stress, Life Satisfaction and Personality Traits. International Journal of Obesity 22(10): 949-957.

Koszegi, Botond and Matthew Rabin (2007). Mistakes in Choice-Based Welfare Analysis. American Economic Review 97(2): 477-481.

Kubey, Robert (1996). Television Dependence, Diagnosis, and Prevention: With Commentary on Video Games, Pornography, and Media Education. In: Tannis M. Williams (ed.). Tuning into Young Viewers: Social Science Perspectives on Television. Thousand Oaks, CA: Sage.

Kubey, Robert and Mihaly Csikszentmihalyi (1990). Television and the Quality of Life. How Viewing Shapes Everyday Experience. Hillsdale, NJ: Lawrence Erlbaum Associates.

Kubey, Robert and Mihaly Czikszentmihalyi (2002). Television Addiction Is No Mere Metaphor. Scientific American 286(2): 74-80.

Laibson, David (1997). Golden Eggs and Hyperbolic Discounting. Quarterly Journal of Economics 112(2): 443-477.

Lakdawalla, Darius and Tomas Philipson (2002). The Growth of Obesity and Technological Change: A Theoretical and Empirical Examination. NBER Working Paper No. 8946, Cambridge, MA. 
Layard, Richard (2005). Happiness: Lessons from a New Science. New York, NY: Penguin.

Loewenstein, George (1999). Because It Is There: The Challenge of Mountaineering ... For Utility Theory. Kyklos 52(3): 315-344.

McElroy, Susan L., Renu Kotwal, Shishuka Malhotra, Erik B. Nelson, Paul E. Keck and Charles B. Nemeroff (2004). Are Mood Disorders and Obesity Related? A Review for the Mental Health Professional. Journal of Clinical Psychiatry 65(5): 634-651.

Muraven, Mark, Dianne M. Tice and Roy F. Baumeister (1998). Self-Control as Limited Resource: Regulatory Depletion Patterns. Journal of Personality and Social Psychology 74(3): 774-789.

Needham, Belinda L. and Robert Crosnoe (2005). Overweight Status and Depressive Symptoms During Adolescence. Journal of Adolescent Health 36(1): 48-55.

O'Donoghue, Ted and Matthew Rabin (2005). Incentives and Self-Control. Mimeo, Cornell University and University of California at Berkley.

OECD (2005). OECD Factbook 2005: Economic, Environmental and Social Statistics. Paris: OECD.

Offer, Avner (2001). Body Weight and Self-Control in the United States and Britain since the 1950s. Social History of Medicine 14(1): 79-106.

Offer, Avner (2006). The Challenge of Affluence. Self-Control and Well-Being in the United States and Britain since 1950. Oxford: Oxford University Press.

Oswald, Andrew and Nattavudh Powdthavee (2007). Obesity, Unhappiness, and The Challenge of Affluence: Theory and Evidence. Economic Journal 117(523): F441F459.

Pearlin, Leonard I., Elizabeth G. Menaghan, Morton A. Lieberman and Joseph T. Mullan (1981). The Stress Process. Journal of Health and Social Behavior 22(4): 337-356.

Putnam, Robert D. (2000). Bowling Alone: The Collapse and Revival of American Community. New York: Simon \& Schuster.

Putnum, Judith Jones and Jane E. Allshouse (1999). Food Consumption, Prices, and Expenditures, 1970-1997. Food and Rural Economic Division, Economic Research Service, Statistical Bulletin No. 965. US Department of Agriculture, Washington, DC.

Rabin, Matthew (1998). Psychology and Economics. Journal of Economic Literature 36(1): 11-46.

Rashad, Inas (2006). Structural Estimation of Caloric Intake, Exercise, Smoking, and Obesity. Quarterly Review of Economics and Finance 46(2): 268-283.

Roberts, Robert E., William J. Strawbridge, Stephane Deleger and George A. Kaplan (2002). Are the Fat More Jolly? Annals of Behavioral Medicine 24(3): 169-180.

Sanz-de-Galdeano, Anna (2005). The Obesity Epidemic in Europe. Discussion Paper No. 1814, IZA, Bonn.

Scollon, Christie Napa, Chu Kim Prieto and Ed Diener (2003). Experience Sampling: Promises and Pitfalls, Strengths and Weaknesses. Journal of Happiness Studies 4(1): 534.

Smith, Trenton G. (2006). Reconciling Psychology with Economics: Obesity, Behavioral Biology, and Rational Overeating. Working Paper No. 2006-4, School of Economic Sciences, Washington State University. 
Sparks, Glenn G. and Cheri W. Sparks (2002). Effects of Media Violence. In: Jennings Bryant and Dolf Zillmann (eds.). Media Effects. Advances in Theory and Research. Mahwah, NJ: Lawrence Erlbaum Associates: 269-285.

Stutzer, Alois (2007). Limited Self-Control, Obesity and the Loss of Happiness. WWZ Discussion Paper No. 0707, University of Basel.

Tangney, June P., Roy F. Baumeister and Angie Luzio Boone (2004). High Self-Control Predicts Good Adjustment, Less Pathology, Better Grades, and Interpersonal Success. Journal of Personality 72(2): 271-324.

Taylor, Paul, Cary Funk and Peyton Craighill (2006). Americans See Weight Problems Everywhere but in the Mirror. A Social Trends Report. Pew Research Center, Washington.

Thaler, Richard H. (1981). Some Empirical Evidence on Dynamic Consistency. Economic Letters 8(3): 201-207.

Weimann, Gabriel (1996). Cable Comes to the Holy Land: The Impact on Cable TV on Israeli Viewers. Journal of Broadcasting \& Electronic Media 40: 243-257.

WHO Europe (2005). The Challenge of Obesity in the WHO European Region. Fact sheet EURO 13.

Williams, Tannis Macbeth (ed.) (1986). The Impact of Television. A Natural Experiment in Three Communities. Orlando, FL: Academic Press.

World Health Organization (2002). The World Health Report 2002. Geneva: World Health Organization. 